\title{
ESSAYS
}

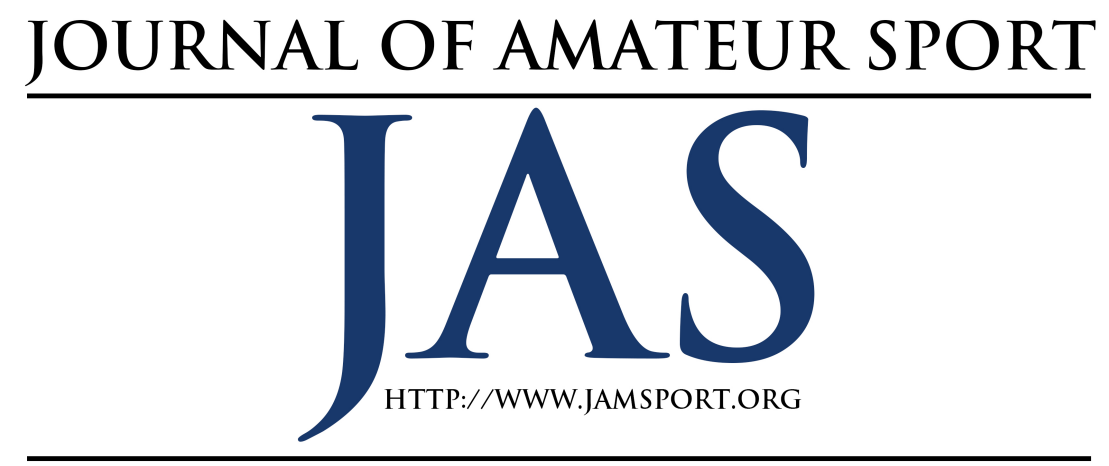

\section{Our Boys and The Last Shot: Examples of the Power of Community Involvement in Underprivileged America}

\author{
Claire C. Schaeperkoetter \\ University of Kansas
}

\begin{abstract}
The central focus of this essay was to examine different socio-cultural structures that affect high school aged athletes in seemingly different impoverished areas in the United States. Specifically, narratives in the popular press books The Last Shot and Our Boys were explored in order to highlight similarities and differences between the high school athletes in these two different urban and rural environments. In all, four factors that showcase the power of community involvement in underprivileged America emerged: the values promoted by the high school coach, the socioeconomic status of the community, the public education system, and the battle between the desire to escape the community and fear of the unknown. The implications of community involvement are discussed and avenues for future research are presented.
\end{abstract}

$\mathrm{M}$ etta World Peace of the New York Knicks, formerly and henceforth referred to as Ron Artest, and Ron Baker of the Wichita State Shockers initially seem to share little more than a passion for basketball and the same first name. Looking at the backgrounds of each of the two illustrates many of the juxtapositions conveyed in two recently published popular press accounts about the high school sports realm: The Last Shot by Darcy Frey and Our Boys by Joe Drape. Although it initially seems that there could be little in common between a high school basketball player from the projects 
of Coney Island in New York City (the scene depicted in The Last Shot) and a high school football player from rural western Kansas (as seen in Our Boys), a deeper look at the backgrounds reveals that similarities do indeed exist.

The individual stories of Ron Artest and Ron Baker parallel the two seemingly disparate worlds that are also articulated in The Last Shot and Our Boys. That is, Artest and Baker, like the two aforementioned books, demonstrate the powerful role sport can play in both rural and urban areas. The purpose of this essay is to further detail the specific roles sport play in both the lives of Ron Baker and Ron Artest and also in the lives of those involved in The Last Shot and Our Boys. An in-depth discussion of the role of the high school coach, socio-economic status and the public education system, and the battle between the desire to escape the community and the fear of the unknown illustrate the reality that sport can serve as a common language for those living in starkly different environments. Possible generalizations to other rural and urban communities are posited and directions for future research are suggested.

During his post-game interview with Doris Burke after his Lakers team won the 2010 NBA Championship, Ron Artest gleefully thanked his psychiatrist for helping him in the deciding Game 7 against the Boston Celtics (Reilly, 2010). Universally lambasted for his role in the
"Malice at the Palace" in 2004, few thought Artest's reputation would ever recover (Weir, 2011). His charitable efforts since that infamous brawl between the Pistons and Pacers, namely his advocacy for mental health programs, led to what he would consider one of his career's crowning achievements: winning the 2010-2011 Walter Kennedy Citizenship Award, given to the player in the NBA who "has displayed outstanding service and dedication to the community" (Weir, 2011, para. 2). A native of Queensboro, New York, Artest returned to his roots to celebrate the NBA championship he won with the skills he developed on the city courts in Queensboro (Reid, 2010). In the aftermath of the Malice at the Palace, critics blamed his upbringing in one of the roughest areas of New York for his foray into the stands at Auburn Palace: "Queensbridge life had hardened Artest. It had made him an angry, impossible-tocoach, misguided young man who, at heart, was his own toughest critic" (Conway, 2010, para. 17). Artest even witnessed a murder during a local YMCA basketball game in 1991 (Conway, 2010).

As conveyed in Darcy Frey's book, The Last Shot, the allure of a college scholarship and the riches of the NBA can occupy the minds of Black youths throughout the projects of New York City (Frey, 2004). It is the stories of triumph over poverty portrayed in the likes of Ron Artest and LeBron James 
that lead many media-consumers to believe the narrative that the NBA is saturated with players from the projects. However, for every Ron Artest and LeBron James, there is a Stephen Curry, Kobe Bryant, or Chris Paul - AfricanAmericans who grew up in middle or upper class, steady households. It has been suggested that "growing up in a wealthier neighborhood is a major, positive predictor of reaching the NBA for both black and white men" (Stephens-Davidowitz, 2013, para. 4). However, the statistics do not reveal how many of those African-Americans in the projects think they are going to make it out of their environment. This notion of defying the odds but then not doing so leads to the heartbreaking stories of people like Russell Thomas from The Last Shot. Such stories illustrate what happens when they do not break the cycle of poverty, particularly when all of their hopes and dreams are based on earning that elusive Division I college scholarship that many think is an express ticket to the NBA.

Ron Baker also sought that elusive Division I scholarship, but not necessarily for the same reasons. Hailing from Scott City, Kansas, a town of about 4,000 people in the sparsely populated region that is western Kansas, Baker played basketball, football, and baseball in high school. The town is passionate enough that the Mayor named March 28, 2013 "Ron Baker Day" because the son of Scott City was in the midst of leading the underdog Wichita State Shockers to the NCAA Final Four. Yet, the town is small enough that there wasn't even a sports bar to celebrate the occasion (Mann, 2013). Weakly recruited out of high school, Baker took up the offer from Wichita State to come as a recruited walk-on. His parents paid Ron's way for his first year, and he was awarded an athletic scholarship at the conclusion of his redshirt freshman season (Mann, 2013). In an interview during the NCAA Tournament with national radio host Jim Rome, Baker said, "I love those guys back home. It's just remarkable where I came from and where I'm at right now. I wouldn't probably be here without the friends and community I grew up in" (Mann, 2013, para. 41).

Explorations of the impact of sport in the rural and urban communities is not solely limited to the anecdotal cases of Artest and Baker or to the in-depth texts of The Last Shot and Our Boys. Other popular press articles and academic articles discuss the role of sport in rural and/or urban communities. The run of Chicago's Little League baseball team to the 2015 Little League Championship and the ensuing vacation of the title because of player eligibility issues sparked a national conversation about youth sport opportunities in an urban setting (Longman, 2014). Lauren Hill, the Division III women's basketball player who was diagnosed with a terminal form 
of cancer, captured the hearts of Americans with her valiant efforts to raise money for cancer research (Feinberg, 2014). Hill played for Mount St. Joseph - a small college in Ohio - and her story initially gained support in her local community. Ensuing conversations at the national level about her efforts note the role of the community in both supporting Lauren and also in bringing national awareness to raising money for juvenile cancer research (Feinberg, 2014). Academic research has been conducted exploring the impact of youth sport participation in the urban and rural setting on issues such as self-esteem, school involvement, and substance use with African-American youth (Taylor \& Turek, 2010). While these specific examples are certainly not an exhaustive account of the existence of articles on the role of sport in the rural and urban community, they do indicate that there is interest in exploring the dynamic between sport participation and the community at large.

Ron Artest's and Ron Baker's stories mimic the narratives in The Last Shot and Our Boys. In all, four basic socio-cultural structures can explain the primary similarities and differences between people like hardwood stalwart Russell Thomas from The Last Shot and gridiron giant Justin Nixon from Our Boys: (1) the values promoted by the high school coach, (2) the socio-economic status of the community, (3) the public education system, (4) and the battle between the desire to escape the community and fear of the unknown.

These two texts were chosen specifically because of the in-depth approach the author took when gleaning information to use in the book. Both Drape and Frey spent more than a school year in the midst of the specific population they wrote about. As such, they were able to use an in-depth approach to really immerse themselves in the fabric of the specific population they were exploring. Furthermore, their rich description and powerful anecdotes add credence to the analysis they delineate throughout their individual texts. Lastly, while both of these books provide such valuable discussions about high school sport in an urban setting (The Last Shot) and a rural setting (Our Boys), their inherent difference of setting explored (urban versus rural) provides a fertile opportunity to explore the salient roles sport can play in youth and high school sport arenas no matter the physical setting. In the following pages, I detail the major themes present in each book and how, while the locations are quite different, many of the narratives are strikingly familiar.

\section{Values Promoted By the High School Coach}

In Joe Drape's narrative depicting the Redmen football team in Smith Center, Kansas, he makes it very clear that for 
Coach Roger Barta, football is a vessel with which to teach lifelong messages of love and respect. Drape leads off the book by quoting Barta as saying, "None of this is really about football... What I hope we're doing is sending kids into life who know that every day means something" (Drape, 2010, p. 1). Barta continues a similar mantra later on when he says,

Fulfilling lives come with doing these things with passion, working constantly on the details that no one but you really sees. It's what we try to pass on to each group of guys we have, that, and the ability to live in harmony with others... Hopefully, in ten or fifteen years, when it matters, these guys will think about something they learned here and make the right decision and have a little success (Drape, 2010, p. 101).

Barta's entire football program is founded on the notion that relationships with your peers, community, and family members are what matter most. Sure, the Kansas state high school record for consecutive victories was at the forefront of the coaches, players, and Smith Center community members, but Coach Barta believed that the wins were a byproduct of a focus on developing relationships and developing a strong work ethic. As such, team chemistry and being a role model in the community were the ultimate goals, and if and when the victories piled up, that would just be icing on the cake.

Now, compare that with this speech from Coach Harstein, the high school coach at Lincoln High School in Coney Island New York that he gave to his players toward the end of the school year: Now listen up. The next few months may be the most important of your life. If you have any pride, you oughtta (sic) bust your ass for the next few weeks in class. Work hard there and on your game, and you can turn a decent college into a good one, a good one into a great one. Tchaka, Russell, Correy - you should all go to Division One school. I promise you: all the hard work you do this summer will pay off. That's what separates the guys who make it from the ones who don't. This is not fun and games. If you just run up and down all summer in the parks, then two years from now, you'll still be in the playground. And it doesn't matter to me. Honestly, I really don't care. You won't be the first to blow it; you won't be the last (Frey, 2004, p. 128). On the one hand, Coach Barta believes in the power of camaraderie and hard work and that wins and college scholarships are an added bonus. On the other hand, Coach Harstein understands the cycle of poverty and the violence and drug problems that come along with it. While it may seem that he is encouraging his players to only look out for 
themselves, he is only doing what he believes is best for the future of his players. Furthermore, Coach Barta is in the fortunate situation of serving the role as coach and life mentor. While Smith Center, like Coney Island, is rife with poverty, there is a community system and fathers in most households that support the upbringing of the youth in the community. Coach Harstein has to serve the role of coach and life mentor in addition to recruiting coordinator and father figure. At Smith Center, the parents of the players had the luxury of seeking out Coach Barta for help when their kids were not behaving at home and were being disrespectful to the parents.

At the request of a parent, Coach Barta spoke to the team about the importance of loving your parents. In a lively speech in the locker room before a practice, Barta said, 'You don't want to spend time with your mommas and dads because you don't think they're very smart... Now I'm telling you this because I think you people need to be reminded that their moms and dads are the people who love them the most... So you guys, listen to your parents. Spend time with them. Tell them you love them (Drape, 2010, p. 89). Coaches everywhere in the projects around the country wish they could give similar speeches. The rub is that the speech and the message would not be applicable.

Players like Russell Thomas in the projects of Coney Island don't have both "mommas and dads" to spend time with because two-parent households are not commonplace. Thus, although it sounds like it would be a good idea in Coney Island to also promote Barta's message of love and the importance of relationships with family and community members, it simply is not realistic to do so. The issue is not simply one of money. There is not a strong support system, academically or socially, to consistently raise kids in a manner that breaks the cycle of living in poverty in the projects. As such, promoting a culture where working your hardest on your basketball skills for the small chance to break that cycle is realistically a good culture to promote. Because, statistically speaking, the player will not make it and they will be right back where most people thought they would be: in the poverty cycle that runs rampant on Coney Island. Trying and failing is accepted because failing to escape Coney Island is the norm.

\section{Socio-Economic Status and the Public Education System}

Smith Center is the definition of the "middle of nowhere," hours away from a city that even boasts a population of more than 30,000 people (Drape, 2010). Coney Island is within the metropolitan area of the largest city in the United States, but for many of its inhabitants, it might as well be in the middle of nowhere as insinuated by Frey when he says, "The streets offer none of the 
bustling commerce and pedestrian life that are great compensations for city living... Despite the concentration of tenants in each building, the project courtyards and walkways often look emptied-out, as if all but the drug dealers have been put under curfew or quarantine" (Frey, 2004, p. 104). It is a community that might as well be in the isolated lands of western Kansas. No one comes and no one goes. College coaches used to come, until it became so dangerous to attend games where riots are commonplace or to do in-home visits with prospects in the tenant buildings that coaches instead choose to focus more of their New York City recruiting in the safer parochial high schools (Frey, 2004).

In Coney Island, the high schools do not provide an oasis from the violence that runs rampant on the streets. Lockers provide hiding places for handguns, security guards and police officers man the entrances and exits to the buildings, and scholastic learning runs a distant second to staying safe while in the building of Lincoln High School (Frey, 2004). Russell Thomas, one of the main characters in the narrative, struggles throughout the timeframe of the book to achieve the minimum SAT score of 700 to qualify academically to play at a Division I NCAA institution. As dedicated as he is with carrying around SAT vocabulary notecards and working on his reading comprehension, a school system in which he never really learned basic math or finished a book made it most improbable that Russell or any other student at Lincoln High would achieve a SAT score that would impress institutions of higher education.

In Smith Center, like in Coney Island, poverty is the norm and not the exception. With an annual per capital income of $\$ 14,983$, Smith Center is in Kansas' fifth poorest county (Drape, 2010). At the same time, however, the community continues to support its public education system and the salary structure in place for teachers makes it so quality educators are committed to stay in Smith Center. Teachers earn an average salary of $\$ 40,000$ and they are regarded within the community as noble leaders for the youth in the area (Drape, 2010). The high school principal has not found any drugs on the premises in his four years at the school. Additionally, the high school is arguably the community's greatest sense of pride. The football team is the pride and joy of Smith Center. Morse Boucher, a Smith Center resident for decades, conveys his loyalties during an interview when he said, "It's more than just winning; they come out of here with a work ethic and sense of caring for each other. I know that's what I'm proudest of. They are the town's ambassadors" (Drape, 58). 
The Battle Between the Desire to Escape the Community and Fear of the Unknown

Although I have certainly painted the portrait of each of these communities as being places that one would like to leave, both Coney Island and Smith Center do provide the one thing many 18 year-olds are terrified of leaving - familiarity. Coney Island is extremely poor. Smith Center is extremely poor. One has a community proud of raising its kids together and knowing they are loved. The other has one of the most concentrated living areas in the country, but neighbors interact with violence and via drug deals. Both communities have been that way for decades and the continuity and familiarity can provide solace for its members. There are particular athletes in both Our Boys and The Last Shot that exemplify this very notion that familiarity can be tempting even if there are opportunities to escape the isolation of the community and to move on to bigger and better things.

In Smith Center, Justin Nixon was known as a beast of a lineman. A sculpted 350 pounds, his size and strength were appealing to college football coaches. His family had lived and farmed in the area for generations. None had received any education beyond high school and it was unknown whether any had ventured more than thirty miles away from Smith Center ever. About Nixon, Coach Barta said, "I think he's got a whole lot on him, and a whole lot he doesn't understand. He doesn't have any aspirations, and that is not his fault. Right now, I think he is afraid of succeeding" (Drape, 2010, p. 41).

Halfway across the country, native Coney Islander Russell Thomas similarly struggled with the idea of leaving home even though he hated nearly everything about Coney Island. His home life was in shambles, brought on by the fact that his father had been absent since he was an infant (Frey, 2004). Taylor had dreams; big ones, but practical ones. He knew the millionaire riches of the NBA were a bit of a long shot. He wanted that college education. Taylor said, "What I really want is to graduate from college, start me a nice little family, and get me a nice little job as a registered nurse" (Frey, 2004, p. 68).

Taylor's dreams seemed practical, but even an impeccable work ethic could not make up for the cards that were stacked up against him. He had never lived anywhere other than Coney Island. And he could not overcome his poor standardized test scores that were a result of years of a failed public education system on Coney Island. The pressure he put on himself and the pressure put on by his family and later his wife ultimately led to the trouble that author Darcy Frey predicted when initially penning the book. Writing the book in the early 1990s and later providing an update ten years later, Frey wrote about Taylor in the '90s 
that, "As much as he hates Coney Island, Russell has never lived anywhere else, and I know that he fears his dark complexion will get him into trouble outside his home turf' (Frey, 2004, p. 199). Russell died in an apparent suicide in 1999 (Frey, 2004).

\section{Concluding Remarks and Continuing Research}

The stories depicted in Our Boys and The Last Shot provide salient examples of the contrast that can exist when looking at athletes from different realms of our country. At the same time, there is a magical thread that weaves through all athletes in our country - a desire to belong. For differing reasons, the community involvement, the economy, the levels of violence in the area, and the public education system contributed to the ceiling of Ron Artest and Ron Baker and create the narrative for basketball players in Coney Island and football players in Smith Center. Poverty does not have to be the overarching contributing factor to a continual cycle of poverty for youths raised in the poorest parts of our country. Smith Center models a system in which community support and a sound public schooling system give kids every opportunity to move on to bigger and better things. And in the case of many of the older generations in Smith Center, happiness is possible even when money is not abundant. However, happiness is more likely when the community is unified. In poverty-stricken areas like
Coney Island, New York, it appears there is less of an opportunity to break the cycle of poverty because of the social and educational infrastructure in place. As such, many kids look to basketball as their only lifeline to a happier life. The odds are strongly stacked against them, and when they do not have the work ethic or the natural abilities to succeed on the court and qualify academically, there is no community support to fall back on.

Although the stories of Artest and Baker and those in Smith Center and Coney Island are particularly salient because of the rich anecdotal evidence they provide, their stores should not be solely confined to their specific setting. Smith Center could arguably be considered to be representative of "Small Town America". Coney Island is not the only impoverished urban area in the United States. The discussions about the intersection of race, social class, and sport that take place Our Boys and The Last Shot represent case study examples of what arguably exists in more generalized settings across the United States. National media coverage about the Chicago Little League baseball team and Lauren Hill at Mount St. Joseph University demonstrate the intersection of race, social class, and community with sport. Such examples in the popular press harken back to the generalizability of the issues conveyed in Our Boys and The Last Shot. 
The Last Shot and Our Boys were chosen for the aforementioned reasons, yet other popular texts and documentary movies exist should the reader have interest in looking at other examples of a text involving a long-term, in-depth immersion of an author into a sport specific setting. Season on the Brink by John Feinstein explores the unique coaching style of Bobby Knight. Feinstein spent the 1985-1986 basketball team immersed in the life and culture of Bobby Night's Indiana University basketball team (Feinstein, 2012). By having such unique access to one of the most storied programs in the country with one of the most bombastic coaches of his era, Feinstein is able to truly give an expert, insider perspective on the coaching style of Bobby Knight (Feinstein, 2012). Similarly, Hoop Dreams, an acclaimed 1994 documentary that details the high school athletic trajectory of two inner-city Chicago kids, juxtaposes the role of athletic talent and socioeconomic status with the academic and athletic opportunities of the two high school basketball players from Chicago (James \& Marx, 1994).

Future research could help address some of the connections between basketball success at the high school level and issues later in life if a college scholarship is never attained. Looking at the numbers of players that play in showcase summer basketball tournaments meshed with the race, zip code, socio-economic status, and quality of education could be insightful. Essentially, both Frey and Drape provided a interesting set of case studies, but some further academic research could further validate or refute the claims and possibly provide further impetus for looking at ways to enhance the public educational systems in even the most poverty-stricken areas.

Claire C. Schaeperkoetter, M.S.E. is a doctoral research fellow at the University of Kansas. She is currently researching organizational structures and socio-cultural dynamics of amateur sport. A former Division III student-athlete and National Champion at Washington University in St.

Louis, Claire has been both a Division III athlete and also an employee in a major NCAA Division I atbletic department. Claire was also the recipient of the 2015 Dr. Robert E. Frederick Scholarship at the University of Kansas. 


\section{References}

Conway, T. (2010, May 28). From

Queensbridge with love: How

Artest's past foreshadowed a Laker

win. Bleacher Report. Retrieved from

http://bleacherreport.com/articles/

397965-from-queensbridge-with-

love-how-artests-past-

foreshadowed-a-laker-win

Drape, J. (2010). Our Boys: A perfect season

on the plains with the Smith Center

Redmen. New York, NY: Times

Books.

Feinberg, D. (2014, October 30).

Women's hoops community rallies around Lauren Hill. Yahoo Sports.

Retrieved from

http://sports.yahoo.com/news/wo

mens-hoops-community-rallies-

around-004020893--ncaaw.html

Feinstein, J. (2012). Season on the Brink.

Simon and Schuster.

Frey, D. (2004). The last shot: City streets.

Basketball dreams. (2nd ed.). New

York, NY: Houghton Mifflin.

James, S. (Director), \& Marx, F. (Writer) (1994). Hoop dreams [DVD].

Longman, J. (2015, February 11). Jackie

Robinson West, a team that won hearts, loses its' Little League title.

The New York Times. Retrieved from

http://www.nytimes.com/2015/02/

$12 /$ sports/jackie-robinson-west-

stripped-of-its-national-little-leaguetitle.html?_r=0

Mann, F. (2013, March 27). Baker's success with Wichita State isn't a surprise in Scott City. The Kansas City Star. Retrieved from

http://www.kansascity.com/2013/0

3/27/4147698/ron-bakers-success-

with-wichita.html

Reed, S. (2010, July 20). Ron Artest

returns to his hometown in

Queens. MTV News. Retrieved from http:/ /www.mtv.com/news/articles /1644087/ron-artest-returns-hishometown-queens.jhtml

Reilly, R. (2010, December 11). Being Ron Artest. ESPN. Retrieved from http://espn.go.com/espn/news/sto ry?id $=5902468$

Stephens-Davidowitz, S. (2013, November 02). In the N.B.A., zip code matters. The New York Times. Retrieved from http://www.nytimes.com/2013/11/ 03/opinion/sunday/in-the-nba-zipcode- matters.html?pagewanted $=1$

Taylor, M. J., \& Turek, G. M. (2010). If only she would play? The impact of sports participation on self-esteem, school adjustment, and substance use among rural and urban African American girls. Journal of Sport Behavior, 33(3), 315-336.

Weir, T. (2011, April 26). Ex-villain Ron Artest wins good citizen award. USA Today. Retrieved from http://content.usatoday.com/comm unities/gameon/post/2011/04/exvillain-ron-artest-wins-good-citizenaward/1 